\title{
Laser Hemorrhoidoplasty: Experience at Aga Khan University Hospital
}

\author{
Abdallah Abdulkarim, Misoi Brian, Gathege Daniel \\ Aga Khan University Hospital
}

Correspondence to: Dr. Abdallah Abdulkarim; Email: abdulkarim.abdallah@aku.edu

\begin{abstract}
Background: Hemorrhoidal disease is the commonest benign anal condition diagnosed in the outpatient setup. Interventional treatment options range widely, from office-based procedures to hemorrhoidectomy. Laser technology increasingly is in use in the field of proctology. We present our index clinical outcomes following laser haemorrhoidoplasty (LHP). Methodology: Retrospective cross-sectional study of 21 consecutive patients who underwent LHP between 2015 and 2018 under a single surgeon. Their outcomes were compared with a group of patients who underwent the standard open hemorrhoidectomy over the same period of time. Results: Postoperatively, $85.7 \%$ of patients postLHP had a better pain score (mild) compared with $66.7 \%$ in the open hemorrhoidectomy group. The mean operative time in minutes was shorter for LHP, $29.67 \pm 17.50$ versus $39.20 \pm 20.77$ in the open group. Duration of hospital stay in days between the two groups were similar; LHP group median=1(1-3), open group median $=1(1-3)$. Rates of infection, recurrence and
\end{abstract}

\section{Introduction}

Hemorrhoidal disease is a common presentation at surgical outpatient clinics; estimated worldwide prevalence is between $2.9 \%$ and $27.9 \%$ (1). Its management is associated with significant healthcare related costs (2). Hemorrhoidal disease can be classified as internal or external, depending on the site of origin in relation to the dentate line. Internal hemorrhoids are further sub-classified from grade 1 to 4 , depending on degree of prolapse and ease of reduction $(3,4)$.

Laser energy is a novel technique that in increasing use in benign anal conditions (5). Probes are used to produce short, high-energy pulses of light that are transformed into heat energy when absorbed by surrounding tissues. Clinically, de-arterialization may be done with or without mucopexy, or with the use of Doppler assistance. When compared with laser hemorrhoidoplasty and other urinary complications were however higher in the laser group, $4.8 \%, 9.5 \%$ and $9.5 \%$ respectively compared with the open hemorrhoidectomy group that were $0 \%, 6.7 \%$ and $6.7 \%$ respectively. Both groups had no reported cases of stool or flatus incontinence. Conclusion: Laser haemorrhoidoplasty is associated with reduced pain scores and shorter operative time than open hemorrhoidectomy. Duration of hospital stay was similar in both groups. The rate of complications was high in the study group.

Keywords: Laser haemorrhoidoplasty, Pain score, Complications, Open hemorrhoidectomy

Ann Afr Surg. 2020; 17(2): 76-79

DOI: http://dx.doi.org/10.4314/aas.v17i2.8

\section{Conflicts of Interest: None}

\section{Funding: None}

(C) 2020 Author. This work is licensed under the Creative Commons Attribution 4.0 International License.

treatment modalities, conventional hemorrhoidectomy is associated with increased operative time, postoperative pain and duration of hospital stay $(6,7)$. Data are scarce on outcomes and complications following laser use in management of symptomatic hemorrhoids in Africa. We present our early experiences with LHP at a teaching hospital and compare its outcomes with the standard of care.

\section{Materials and Methods}

This is a retrospective single center observational study of 21 consecutive patients who underwent laser haemorrhoidoplasty under one surgeon from 2015 to 2018. We compared their outcomes with 15 patients who underwent open hemorrhoidectomy over the same period. Patients were evaluated at the clinic and booked for surgery if symptoms were refractory to conservative 
treatment. Both surgical options were offered preoperatively and informed consent obtained. Intraoperatively, patients were placed in lithotomy position and examined under anesthesia to confirm columns involved and degree of severity based on Goligher's classification.

Patients undergoing laser hemorrhoidoplasty had a mucosal incision made at the distal end of the hemorrhoid and a size 980nm laser scope inserted into the submucosal space and advanced to the base of the hemorrhoid. Pulsed boluses of energy at 15 watts were released with confirmation of blanching of the hemorrhoidal tissue, up to a total of 1200 watts. Where indicated, a mucopexy was done. The patients received a pudendal nerve block after the procedure.

In the open hemorrhoidectomy technique, after examination under anesthesia, involved columns were noted and hemorrhoidal tissue grasped and retracted with tissue clamps to facilitate trans-fixation of the base of the pedicle. An elliptical incision is made over the perianal skin and scissors are used to dissect in the plane between hemorrhoidal tissue and fibers of the sphincter muscles. Hemorrhoidectomy was done upon reaching the vascular pedicle and the base of the wound inspected for any bleeding and hemostasis achieved.

Both procedures were done by a single surgeon with training in both techniques. Post-operatively, patients followed a protocol that entailed pain control using pudendal block and regular standard non-opioid painkillers, laxatives and ice packs for those who underwent LHP or sitz baths for those who were post open hemorrhoidectomy.

Pain scores were assessed every six hours by nursing staff and the mean pain score taken over the duration of patient stay. These were rated in degree of severity from 0 to 10 . Mild score was assigned if score was between 0-2, moderate if 3-5 and severe if 6-10. Operative time was recorded in minutes and duration of hospital stay in days. Post-operative complications including recurrence, urinary outflow symptoms, infection and stool or flatus incontinence were described as rates. Recurrence was defined as presence of prolapsed tissue or persistence of post-operative bleeding with demonstrable hemorrhoids on anoscopy. Data was analyzed by use of SPSS version 20.

\section{Results}

LHP was done on 21 consecutive patients. 10 were female and 11 were males, with a mean age at presentation of $39.29 \pm 8.730$ years. The most common hemorrhoidal grade was $3(66.7 \%)$ followed by $4(19 \%)$ then $2(14.3 \%)$.

The open procedure had 15 patients, 6 female and 9 males. The mean age at presentation was $42.20 \pm 15.853$. Nine patients $(60 \%)$ had grade 4 hemorrhoids, $4(26.7 \%)$ had grade 3 while $2(13.3 \%$ ) had grade 2 (table 1 ).

\begin{tabular}{|c|c|c|}
\hline Characteristic & $\begin{array}{l}\text { Laser } \\
\text { hemorrhoidoplasty } \\
(n=21)\end{array}$ & $\begin{array}{l}\text { Open } \\
\text { hemorrhoidectomy } \\
(n=15)\end{array}$ \\
\hline $\begin{array}{l}\text { Age at presentation } \\
\text { (years) }(\text { mean } \pm \text { SD) }\end{array}$ & $39.29 \pm 8.730$ & $42.20 \pm 15.853$ \\
\hline $\begin{array}{c}\text { Gender } \\
\text { Female } \\
\text { Male }\end{array}$ & $\begin{array}{l}10(47.62 \%) \\
11(52.38 \%)\end{array}$ & $\begin{array}{l}6(40.0 \%) \\
9(60.0 \%)\end{array}$ \\
\hline $\begin{array}{c}\text { Grade } \\
2 \\
3 \\
4\end{array}$ & $\begin{array}{l}3(14.29 \%) \\
14(66.67 \%) \\
4(19.04 \%)\end{array}$ & $\begin{array}{l}2(13.33 \%) \\
4(26.67 \%) \\
9(60.0 \%)\end{array}$ \\
\hline
\end{tabular}

After LHP, 18 patients (85.7\%) had mild pain scores, $1(4.8 \%)$ patient was classified as having moderate pain score and two (9.5\%) had severe pain scores. The comparative open surgery group had 10(66.7\%), $3(20 \%)$ and $2(13.3 \%)$ with mild, moderate and severe pain scores respectively. Whereas the laser group had a lower mean pain score during their admission than the open group, this was not statistically significant $(1.05$ vs 2.00 , mean difference- 0.952, CI- 2.704-0.799, $\mathrm{p}=0.277$ ).

The mean operative times were shorter in the LHP group (29.67+-17.50 vs 39.20+-20.77 minutes). The median number of days admitted to the ward were similar in both groups, LHP 1 day (1-3), open group 1 day (1-3). In the LHP group, there was a strong positive correlation between recorded pain scores and duration of hospital stay, $\mathrm{r}=0.510 n=21 \mathrm{p}<0.005$, and operative time and duration of hospital stay, $r=0.761 \mathrm{n}=21, \mathrm{p}<0.005$

Complications were observed more frequently in the laser group $(33.3 \%)$ than in the open group (20.0\%). In the laser group, a higher proportion of patients had recurrence of symptoms than the open group $(9.5 \%$ vs $6.7 \%, \mathrm{OR}=2.33,95 \%$ CI $0.218-24.923, \mathrm{p}=0.483)$. The same trend was also seen in proportion of patients with urinary outflow complications $(9.5 \%$, vs $6.7 \%$, $\mathrm{OR}=1.474,95 \%$ CI $0.121-17.913, \mathrm{p}=0.761)$ and those who complicated with infection $(4.8 \%$ versus $0 \%)$. Both groups had no reported cases of stool or flatus incontinence.

On further analysis, multilinear regression showed no relationship between grade of hemorrhoid $(p=0.571)$, 
type of surgical intervention $(\mathrm{p}=0.796)$ and development of any complication $(\mathrm{F}(2,20)=0.180, \mathrm{p}=0.837) \mathrm{R} 2=0.018$ (Table 2).

Table 2: Outcomes in laser hemorrhoidoplasty and open hemorrhoidectomy groups

\begin{tabular}{lllll}
\hline Outcome & $\begin{array}{l}\text { Laser } \\
(n=21)\end{array}$ & $\begin{array}{l}\text { Open } \\
(n=15)\end{array}$ & OR & P value \\
\hline $\begin{array}{l}\text { Pain score } \\
\text { categories }\end{array}$ & $\begin{array}{l}18(85.7 \%) \\
\quad \text { Mild }\end{array}$ & $\begin{array}{l}10(6.8 \%) \\
3(20.0 \%)\end{array}$ & - & - \\
$\quad \begin{array}{l}\text { Moderate } \\
\quad \text { Severe }\end{array}$ & $2(9.5 \%)$ & $2(13.3 \%)$ & & \\
$\begin{array}{l}\text { Mean pain score } \\
\text { Mean operative }\end{array}$ & 1.05 & 2.00 & - & 0.277 \\
$\begin{array}{l}\text { time (mean } \pm \text { SD) } \\
\text { (hours) }\end{array}$ & $29.67 \pm 17.5$ & $39.20 \pm 20.7$ & - & 0.146 \\
$\begin{array}{l}\text { Median duration } \\
\text { of hospital stay } \\
\text { (days) }\end{array}$ & 0 & 7 & & \\
$\begin{array}{l}\text { Rate of infection } \\
\text { Rate of }\end{array}$ & $4.8 \%$ & 1 & - & - \\
recurrence & $9.5 \%$ & $6.7 \%$ & 2.33 & 0.483 \\
$\begin{array}{l}\text { Rate of urinary } \\
\text { complications }\end{array}$ & $9.5 \%$ & $6.7 \%$ & 1.474 & 0.761 \\
\hline
\end{tabular}

\section{Discussion}

The exact pathophysiology of hemorrhoidal disease is yet to be clarified could be multifactorial in etiology (8). Several theories exist, these include disintegration of the anchoring supporting tissue of anal cushion (9), increased inflammatory activity in prolapsed tissue (10), increased caliber and flow of terminal branches of superior rectal artery (11) or increased neo-vascularization from endoglin and CD 34 expression (12).

This understanding led to development of management strategies to treat symptomatic hemorrhoidal disease. Goals of operative treatment include decreasing vascular inflow and reducing redundant tissue by excision or by fixing hemorrhoidal tissue to the rectal wall. Conventional hemorrhoidectomy remains the standard of care with respect to long term patient outcomes $(13,14)$. However, compared with the less invasive methods of treatment, its use is associated with high post-operative pain scores and slower return to work $(14,15)$

Laser haemorrhoidoplasty as described by Dal Monte et al. has an efficacy of up to $92 \%$ in symptomatic grade 2 to 4 hemorrhoids (16). Its use is associated with short hospital stay and mild post-operative pain (17). This was consistent with our findings when we noted a median hospital stay of one day and most patients $(85.7 \%)$ having mild pain scores post-operatively. Of patients who underwent laser haemorrhoidoplasty, 9.5\% had severe pain scores, compared with $13.3 \%$. One patient had thrombosed external hemorrhoids that required reoperation two weeks later and the other had an ineffective caudal block. We subsequently changed our protocol to intervene only in patients with internal hemorrhoids and we adopted pudendal blocks as a modality of post-operative analgesia.

Operative time was short than in those who underwent open hemorrhoidectomy. This finding was consistent with the findings by Simillis et al. and Alsisy et al. The authors noted decreased operative time when comparing laser hemorrhoidoplasty to open hemorrhoidectomy; this could be explained by the increased operative bleeding observed in the latter group $(14,18)$. In our study, however, we did not look at intra-operative blood loss and its correlation to operative time between the two groups.

Duration of hospital stay was similar in both laser and the comparative group. This was at variance to shorter hospital stay when comparing laser to conventional hemorrhoidectomy in grade 3 (19), or grades 3 and 4 hemorrhoids (14). This finding can be explained by the skewed data in patients who underwent LHP without pudendal blocks subsequently developed higher pain scores post-operatively, necessitating longer hospital stays. Longer operative times associated with the learning curve of a new procedure also explained the unexpected longer hospital stay. This was in keeping with a strong positive correlation between intra-operative time and pain scores with duration of hospital stay observed in the LHP group. These correlations were not seen in the open hemorrhoidectomy group.

Complication rates were observed to be higher in the laser group. In the LHP group, we noted high recurrence rates than in the open group. Giordano et al. in his systematic review of Doppler assisted trans-anal hemorrhoidal de-arterialization, showed an overall recurrence rate of $9 \%$ (17). This value approximated our recurrence rate of $9.5 \%$. One patient had wound discharge that was treated conservatively and resolved within a week. There were no patients with wound infections in the comparative group. Grade of hemorrhoid and type of surgical intervention did not predict development of any complication on further analysis.

Limitations in our study include the small number of reviewed cases that could have influenced results obtained from statistical testing. Further studies are needed to explore the emerging themes and compare laser haemorrhoidopasty and other less invasive methods in our setup.

Our experience is that LHP use is associated with fewer patients with severe pain scores, and with shorter operative time. Duration of hospital stay was similar 
between the two groups; however, recurrence rates and wound complications are higher when compared with conventional hemorrhoidectomy.

\section{Conclusion}

Laser haemorrhoidoplasty is associated with less pain scores and shorter operative times however patients have to be counselled on possibility of higher complication rates than with conventional hemorrhoidectomy. We propose routine use of pudendal nerve block to provide postoperative analgesia.

\section{References}

1. Rogozina V. Hemorrhoids. Eksp Klin Gastroenterol. 2002; (4):93-6, 134.

2. Yang J, Peery A, Lund J, et al. Burden and Cost of Outpatient Hemorrhoids in the United States Employer-Insured Population, 2014. Am J Gastroenterol. 2019; 114(5):798-803.

3. Davis B, Lee-Kong S, Migaly J, et al. The American Society of Colon and Rectal Surgeons Clinical Practice Guidelines for the Management of Hemorrhoids. Dis Colon Rectum. 2018; 61(3):284-92.

4. Wald A, Bharucha A, Cosman B, et al. ACG clinical guideline: management of benign anorectal disorders. Am J Gastroenterol. 2014; 109(8):1141-57.

5. Wilhelm A. A new technique for sphincter-preserving anal fistula repair using a novel radial emitting laser probe. Tech Coloproctol. 2011; 15(4):445-9.

6. Laughlan K, Jayne D, Jackson D, et al. Stapled haemorrhoidopexy compared to Milligan-Morgan and Ferguson haemorrhoidectomy: a systematic review. Int J Colorectal Dis. 2009; 24(3):335-44.

7. Maloku H, Gashi Z, Lazovic R, et al. Laser Hemorrhoidoplasty Procedure vs Open Surgical Hemorrhoidectomy: A Trial Comparing 2 Treatments for Hemorrhoids of Third and Fourth Degree. Acta Inform Med 2014; 22(6):365-7.
8. Lohsiriwat V. Treatment of hemorrhoids: A coloproctologist's view. World J Gastroenterol. 2015; 21(31):9245-52.

9. Thomson H. The anal cushions--a fresh concept in diagnosis. Postgrad Med J. 1979; 55(644):403-5.

10. Han W, Wang Z, Zhao B, et al. Pathologic change of elastic fibers with difference of microvessel density and expression of angiogenesis-related proteins in internal hemorrhoid tissues. Zhonghuawei changwaikezazhi. 2005; 8(1):56-9.

11. Aigner F, Bodner G, Gruber H, et al. The vascular nature of hemorrhoids. J Gastrointest Surg. 2006; 10(7):1044-50.

12. Chung Y, Hou Y, Pan A. Endoglin (CD105) expression in the development of haemorrhoids. Eur J Clin Invest. 2004; 34(2):107-12.

13. Lumb K, Colquhoun P, Malthaner R, et al. Stapled versus conventional surgery for hemorrhoids. Cochrane Database Syst Rev. 2006 4:CD005393.

14. Simillis C, Thoukididou S, Slesser A, et al. Systematic review and network meta-analysis comparing clinical outcomes and effectiveness of surgical treatments for haemorrhoids. Br J Surg. 2015; 102(13):1603-18.

15. Shanmugam V, Hakeem A, Campbell K, et al. Rubber band ligation versus excisional haemorrhoidectomy for haemorrhoids. Cochrane Database Syst Rev. 2005; 3:CD005034.

16. Dal Monte PP, Tagariello C, Giordano P, et al. Transanal hemorrhoidal dearterialisation: non excisional surgery for the treatment of haemorrhoidal disease. Tech Coloproctol. 2007; 11(4):333-9.

17. Giordano P, Overton J, Madeddu F, et al. Transanal hemorrhoidal dearterialization: a systematic review. Dis Colon Rectum. 2009; 52(9):1665-71.

18. Alsisy A, Alkhateep Y, Salem I. Comparative study between intrahemorrhoidal diode laser treatment and Milligan Morgan hemorrhoidectomy. Menoufia Med J. 2019; 32(2):560-5.

19. Maloku H, Lazović R, Terziqi H. Laser hemorrhoidoplasty versus Milligan-Morgan hemorrhoidectomy—short-term outcome. Vojnosanitetski Pregled. 2019; 76(1):8-12. 